\section{CLINICAL LECTURE ON}

\section{D I O P A T H I C A N $Æ$ M I A. Delivered in the City of Dublin Hospital.}

By J. M A G E E F I N N Y, M.D.Univ. Dubl., Fellow of the King and Queen's College of Physicians in Ireland; Visiting Physician to, and Lecturer on Clinical Medicine in the Hospital.

Gentlemen,-The subject of my lecture to-day-Idiopathic Anæmia -is one of great rarity, and one in which, in the last few years, considerable interest has been awakened. To you, however, it has a special interest, as the cases which I shall use as illustrations of the disease have been under your immediate observation in the medical wards of this hospital, while, in the daily record of the symptoms and in the observation of the progress of each case, some of you have assisted me not a little. The disease is everywhere a rare one, but more particularly is it so in Ireland. With the exception of one case, recorded by Dr. Purser in the Dublin Fournal of Medical Science, November 1877 , there has not been another published instance in this country. It is, however, both possible and probable that in this, as in other countries, idiopathic anæmia has been mistaken for renal disease, cancer, fatty heart, and chlorosis. Such seems to have been the case with Andral and others. It is not a new disease, and yet you will probably not find it described, if mentioned, in your text-books, or even in books of reference. To Addison is due the credit of having described its distinctive features, and of having given it an identity it had not possessed prior to his time. As his description of this form of anæmia is still the best, I shall read the following extract from his writings (New Sydenham Society, vol. xxxvi, p. 212).

"For a long period, I had from time to time met with a very remarkable form of general anæmia, occurring without any discoverable cause whatever-cases in which there had been no previous loss of blood, no exhausting diarrhœea, no chlorosis, no purpura; no renal, splenic, miasmatic, glandular, strumous, or malignant disease. Accordingly, in speaking of this form in clinical lecture, I, perhaps with propriety, applied to it the term 'idiopathic', to distinguish it from cases in which there existed more or less evidence of some of the usual causes or concomitants of the anæmic state. The disease presented in every instance the same general character, pursued a similar course, and, with scarcely a single exception, was followed, after a variable period, by the same fatal result. It occurs in both sexes, generally, but not exclusively, beyond the middle period of life; and so far as I at present know, chiefly in persons of a somewhat large and bulky frame and with a strongly marked tendency to the formation of fat. It makes its approach in so slow and insidious a manner that the patient can hardly fix a date to his earliest feeling of that languor which is shortly to become so extreme. The countenance gets pale; the whites of the eyes become pearly; the general frame flabby rather than wasted; the pulse, perhaps, large, but remarkably soft and compressible, and occasionally with a slight jerk, especially under the slightest excitement; there is an increasing indisposition to exertion, with an uncomfortable feeling of faintness or breathlessness on attempting it; the heart is readily made to palpitate; the whole surface of the body presents a blanched, smooth, and waxy appearance; the lips, gums, and tongue seem bloodless; the flabbiness of the solids increases; the appetite fails; extreme languor and faintness supervene; breathlessness and palpitations being produced by the most trifling exertion or emotion; some slight œedema is probably perceived about the ankles; the debility becomes extreme. The patient can no longer rise from his bed; the mind occasionally wanders; he falls into a prostrate and half-torpid state, and at length expires. Nevertheless, to the very last, and after a sickness of perhaps several months' duration, the bulkiness of the general frame and the obesity often present a most striking contrast to the failure and exhaustion observable in every other respect. With perhaps a single exception, the disease, in my own experience, resisted all remedial efforts, and sooner or later terminated fatally."

After Addison's death, the disease seems to have been forgotten; and it was not until 1872, that Biermer of Zürich, by publishing fifteen cases of extreme anæmia, which he termed "Progressive Pernicious Anæmia", resuscitated the interest of the profession in it. Since then, numerous instances have been recorded, both at home and abroad. To those of you who may have special interest in it, I would suggest the perusal of an admirable résumé of the literature bearing on this subject by Dr. Pye-Smith in the London Medical Record, vol: v, pp. 314 and 437, and an excellent lecture by Dr. Mackenzie in the Lancet, December 1878 .

CASE I. Profound Ancmia; Occasional Attacks of Diarrhoa; Abdominal Pain; Irregular and High Elevations of Temperature; Marked Alterations in the Corpuscles of the Blood: Treatment by Arsenic; Recovery. (Reported by Mr. Mason, Resident Medical Pupil.)-Thomas H., aged 27, married, clerk, was admitted into the City of Dublin Hospital on November 29th, 1877. Up to four years before admission, from which time he dates his illness, he had been a strong robust man, weighing twelve stone. His habits were regular and temperate; and his occupation as house-agent's clerk gave him plenty of out-door exercise. His mother is alive and well; but his father died of fatty heart. He has several children, who are all strong and healthy, He never had syphilis or miasmatic fever. Twelve years ago, he went to India, remaining there two years in the enjoyment of excellent health. In 1873, he suffered from dyspeptic troubles, flatulence, and constipation; and without being able to give any better account of his illness or more accurately to define its nature, he says he remained in a state of general bad health for fully nine months. The three succeeding years, he was in tolerably good health; and then again, in 1876 , he became unwell. The prominent symptoms were great lassitude and inertness, loss of natural colour, changing to green and yellow; emaciation; and, after a time, diarrhœa. While suffering from the bowels, he experienced pain, persistent and accompanied with a dragging sensation in the region of the liver. He did not know if he had jaundice; his skin was, however, "yellow". On this occasion, he went under treatment in one of the metropolitan hospitals, where he remained a month, feeling little, if anything, better when he left. He derived, however, much benefit from the treatment of a medical man under whom he subsequently placed himself; and he recovered so far as to be able to resume his occupation. During this attack of illness, in 1876 , he stated that for thirteen weeks he passed "black and nasty stuff" from his bowels, "and the pain in his liver was relieved by the motions"; but as to the nature of the discharge he was unable to speak. It is, however, more than frobable it was but the evacuation following treatment by iron.

In the beginning of September in the year 1877 , he experienced muscular weakness, and he noticed he lost colour, his hands, cheeks, and ears becoming unusually white and pallid. A severe pain also seized him in the old place in his right side. He did not, however, give up all attempts to work on, till a sharp attack of diarrhea in October, which lasted without intermission for ten days, confined him to his bed, and weakened him so much as to render him unable to leave it till the day of his admission to hospital.

The following were his condition and the symptoms he presented on admission. He was a man of five feet seven inches in height, eyes blue, hair of a light brown. His skin was peculiarly pale, more sallow than simply bloodless. The colour of the ears, nostrils, and fingers, perhaps more than elsewhere, was of a remarkable semitransparent waxy hue, and the mucous membrane of the eyelids, tongue, and lips was white and blanched. There was no dropsy, though, after standing a little, œedema of the ankles was produced. The patient was so weak as to be hardly able to sit up in a chair for an hour; and, after a short time, even this was too much, and he was obliged to remain in bed. A careful physical examination, frequently repeated, of the organs of the body, failed to discover any change of their size, situation, or nature, except slight enlargement downwards of the liver. Beyond furring of the tongue, loss of appetite, constipation, and tenderness and pain over the seat of the liver, the symptoms were solely those of anæmia and general debility. The pulse, on admission, was Ioo, small and compressible; temperature normal ; heart-sounds normal, but weak. Loud venous murmurs were audible in the neck, and noises in the ears were much complained of. The urine was free from sugar and albumen, and was normal in colour and quantity. Although the patient complained of considerable and, at times, acute pain over the upper border of the liver and the mammary region, physical examination of the lungs and liver alike failed to discover anything which might be considered as its cause. His arms and legs were flabby rather than attenuated, while a very fair amount of fat covered the thorax and abdomen. As there was an absence of evidence of malignant disease, phthisis, or chronic splenic enlargement, and an absence of all history of any drain of pus or blood from any part of the body, or of long and deleterious residence in hot countries, or of attacks of intermittent fever, it became a matter of no little difficulty to make any closer diagnosis of the disease than to saywhat was self-evident to the veriest tyro-that the man suffered from anæmia. It was, indeed, easier to mark what the cause of this anæmia was not, than to affirm positively what it was. It was some time before 
a positive diagnosis was arrived at; not until the blood had been examined, and the treatment by iron had utterly failed to justify its continuance.

Without any assignable cause whatever, on three occasions in the months of December and January (while he was under the care of my colleague Dr. Benson), the temperature suddenly ran up to a high fever range, and nearly as quickly subsided. Two of these exacerbations were carefully noted by my clinical clerk Mr. Mason (vide tables). The first occurred a few days after admission. On the morning of December 5th, the fever stood at $104.4^{\circ}$, falling a degree by the evening, and to $99.6^{\circ}$ next morning. It rose to $102^{\circ}$ that evening, sinking to $99^{\circ}$ on the morning of the 7 th. It seemed to follow no rule of the continued fevers, as the morning heat at times exceeded that of the evening; and the pulse did not reach 110 , while the temperature stood at 104.4. The whole attack lasted nine days. The second attack was equally sudden in its onset, and alike in its duration, but it was more severe. On the evening of January 18 th, the thermometer recorded the alarming temperature of $106^{\circ}$. Next morning, it sank to $99^{\circ}$. It again rose in the evening, but only to $104.2^{\circ}$, and fell on morning of 20 th to $98.4^{\circ}$. For the three following days, it rose to Ior $4^{\circ}$, being higher by over a degree in the morning than in the evening; and then, seemingly without any cause, on the $24^{\text {th }}$, the maximum temperature reached $104^{\circ}$, and the pulse 1 16. This exacerbation was followed by a proportionately deep depression, and in two days the attack passed away.

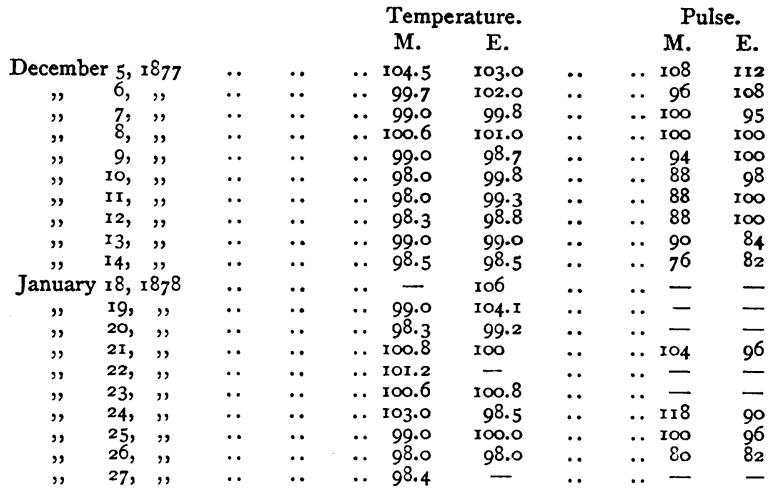

These pyrexial attacks seemed to have nothing in common with remittent or intermittent malarious fever, as there were no stages of heat and cold, and they did not subside by sweating. As might be expected, after each of these attacks, the patient became weaker and more prostrated.

As the disease from which the patient suffered seemed to be very unusual, and, in spite of every treatment, the debility became more pronounced, the patient was seen by several of my medical friends, as well as by my colleagues, including Dr. Hudson, Professor Moore, Professor Purser, and Dr. R. J. Harvey. To the two latter gentlemen I am much indebted, for they rendered me valuable assistance in making the microscopical examination of the blood, and in noting the very remarkable changes in the size and shape of the red corpuscles.

I examined the blood for the first time on February 21st. Its altered characters were so new to me, that $I$ asked Dr. Purser to examine it with me, as I was anxious to have his help, not alone for his skill as a microscopist, but because of the experience he had acquired in the case of idiopathic anæmia to which I have referred.

On March 2 Ist, the blood, drawn by a prick of a needle, issued as a thin fluid of a very much paler colour than normal; the drops it formed were very small, and it stained the handkerchief a lake colour. This loss of colour was better seen under the microscope. There was no increase of the white cells; the red corpuscles did not form rouleaux, but lay either separate or in small clusters. They were very noticeably reduced in number. Several large corpuscles standing by themselves caught the eye at once, and for a moment were thought to be white cells; but closer inspection readily disabused this conception, as they were non-nucleated and of a yellowish colour. In addition to these large corpuscles, there were $(a)$ a very considerable number of cells, much smaller than the normal red corpuscle, even to quarter its size, but having its characteristics; and $(b)$ other strange-looking cells of every size and shape, oval, pear-shaped, bowl-shaped, crenated, and tailed (vide diagram). Aware of the frequency of retinal hæmorrhages in idiopathic anæmia, the eyes, both before and after the employment of atropine, were examined by my colleague Dr. Loftie Stoney, ophthalmic surgeon to the hospital. Beyond pallor of both retinæ and some dilata- tion of the veins, there was nothing abnormal observed-no streaks or punctate ecchymoses.

The diagnosis of idiopathic anæmia which I made when first I examined the blood was now fully confirmed; and the question most diffcult to answer was how best to treat the disease, so as if possible to rescue the patient from that fatal termination, to which his corpselike appearance seemed to be strongly pointing. I had, acting on the

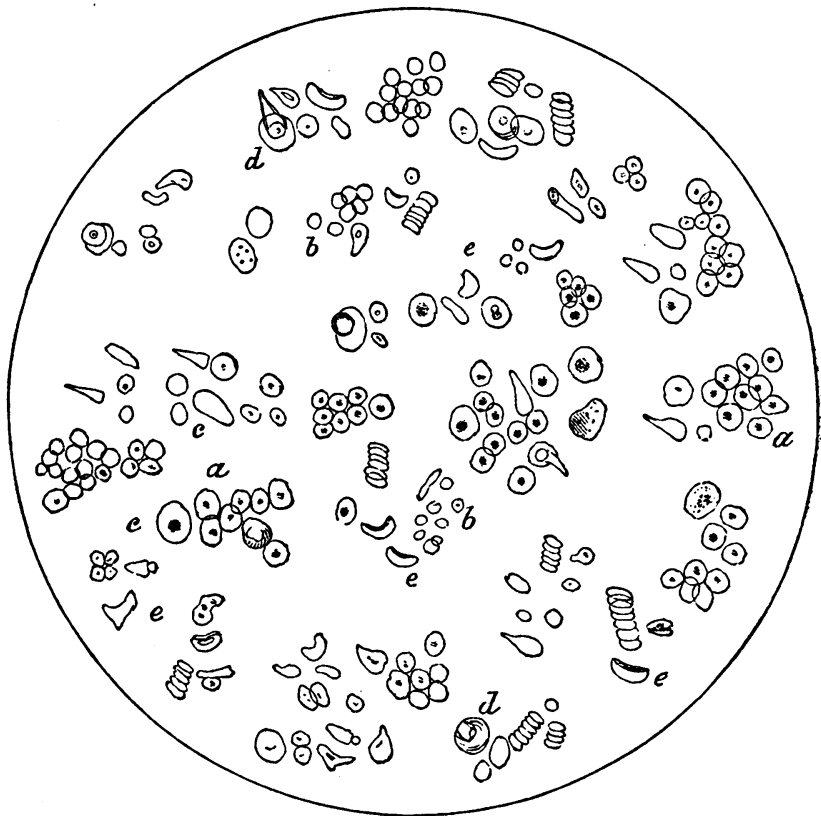

Fig. x.- $a$ a. Clusters of Normal Red Corpuscles. $b$ b. Microcytes. $c c$. Large Coloured Corpuscles. $d$. Overlying Corpuscles. $e$. Irregular Masses.

indication for iron, administered this metal in every form, and in the fullest doses, without seemingly any, even the slightest, benefit. I therefore determined to employ arsenic, partly empirically, and partly from the confidence its use had given me in the management of fatty heart and its anæmic symptoms. I was then unaware that Dr. Byrom Bramwell had found the best results from the use of arsenic in this disease.

On March 15th, I gave him Fowler's solution in three-minim doses, three times a day, in an ounce of infusion of gentian. Never was I so surprised as at the result of this treatment; for in less than a week improvement became manifest, and, by the end of a month, the patient was able to leave his bed without fainting, and to sit by the fire in an easy chair. The blood also, in April, showed commensurate improvement. No longer did it run down the finger in a stream, but presented a full drop and all the macroscopic appearances of healthy blood. The red corpuscles were increased in number; and although the small round and the large non-nucleated cells were visible, their number was greatly less, while the healthy discs showed a decided tendency to adhere together.

This improvement went on steadily; the patient put on flesh gradually, the pallid waxy hue became less pronounced, and, though. weak and easily fatigued, he was able to leave the hospital for The House of Rest in Merrion on April 3 oth, where he remained a month. For two months without intermission, the arsenic was taken, the dose having been increased to four and five minims. In the beginning of June, this patient went back to his occupation, and, owing to the kindness of his employer, he was permitted to do only light work. He visited me on June I7th. I saw a marked change; the pearly colour of the sclerotics was gone; the mucous membranes of the eyelids, lips, and gums were red, and the whole appearance of the man was very much altered for the better, while the lemon tint of the face had quite disappeared. The patient expressed himself, "that his appetite was very good, and, except for the stiffness of his ankles" (due to slight œdema), "he had not felt so well for the last ten years".

I examined his blood on this occasion, and, with the exception of a few solitary small corpuscles which remained in the spaces left by the clusters and rouleaux of healthy corpuscles, it appeared normal. The urine was also normal, specific gravity 1018, free from albumen. 
He has ever since been under my observation ; as occasionally during the last eighteen months, whenever he has suffered from indigestion or constipation, he has paid me a visit, dreading lest these symptoms should indicate a return of his old complaint. He has grown stout and strong; his hair, which had been thin and light-coloured, has become strong, thick, and dark, and he is closely and efficiently fulfilling the arduous and constant duties attendant on his office.

CASE II. Causeless Anamia: Frequent Vomiting: Constant Abdominal Pain: Extreme Prostration: Universal Bloodlessness: Alterations in Shape and Size of the Red Corpuscles: Absence of all Fever: Treatment by Arsenic: Recovery.-Joshua C., a shoemaker, aged 48, was admitted under my care to hospital, on the order of my colleague Dr. Fitzgibbon, on August Ist, 1878. This patient had been for a short time in 1877 under my care, suffering from anæmia, and complaining of vomiting and severe gastric pain. At that time, I was unable to arrive at any positive diagnosis; but I confess I inclined towards the view of his case being one of cancer of the stomach, although I failed to discover any abdominal tumour or any implication of organs elsewhere. After he left hospital in 1877 , somewhat relieved, he was under medical treatment in two other hospitals, and finally was discharged as an incurable case. His wife and friends then endeavoured to have him admitted to the Hospital for Incurables as a case of cancer of the stomach ; and, for the purpose of obtaining a medical certificate to that effect, Dr. Fitzgibbon was asked to see him. Having witnessed the almost miraculous recovery Case I (Thos. H.) had made, Dr. Fitzgibbon, considering it a similar case, refused the certificate until he had been subjected to my treatment and been under my care.

I happened to be in the ward, in company with some of you, gentlemen, when this patient was carried up in the hospital-chair by the porters. Such a miserable, old-looking, worn-out spectre I have rarely witnessed. His dark hair, which was worn long, brought out in striking contrast the sallow pallor of his face and lips; while his black large eyes, with bluish sclerotics, seemed to start out of his head. The patient was thin; and his face, hands, legs, and arms were wasted; but the abdomen was covered with a sensible layer of fat. All the usual symptoms, subjective and objective, of anæmia were present, such as breathlessness, palpitations, fainting, coldness of extremities. The pulse was quick, I12; heart's first sound short and abrupt, accompanied with a basic blowing sound; and there were venous murmurs in the neck. The patient presented to a marked degree the listlessness and apathy which have been noticed in idiopathic anæmia. The temperature was frequently noticed during his stay of eight weeks in hospital, and it was never above normal, but rather subnormal, usually ranging from $97.7^{\circ}$ to $98^{\circ}$ in the axilla, and under the tongue not exceeding $98.4^{\circ}$. The patient's chief complaint-in fact, his only complaint, except that of debility-was a constant severe pain in the epigastrium and painful vomiting after every kind of solid food. In the same situation, there was decided tenderness to the touch or pressure. The tongue was glazed and red at the tip, and the teeth were loose and corroded near the gum. The most careful examination failed to point to any organic disease. Particular attention was directed to the liver, spleen, kidneys, and stomach; but I could not satisfy myself that any abnormal condition of these organs existed. No tumour of the stomach was detected, nor any evidence of ulceration which would account for the frequent vomiting.

The blood, which was obtained with some little difficulty, a deep puncture being necessary to produce a single drop, was of thin consistence, and ran down the finger like spirit, leaving a very faint stain. Under the microscope, the red corpuscles were much diminished in number and did not run into rouleaux. In fact, the appearance tallied closely with that of Case $\mathrm{I}$ in February. There were, however, fewer small red corpuscles, and the tailing of the larger ones was not so marked. There was no increase of the white cells. The subjoined diagram (vide diagram) exhibits the irregularity of the corpuscles. This drawing (which was made by the camera by William Henry Line, A.B., my medical resident pupil) does not represent the appearances of a single field, but shows the irregular corpuscles in several specimens, which, as soon as they appeared in a field, were at once marked down.

The diagnosis of idiopathic anæmia was arrived at, and the same therapeutic as was so serviceable in Case I-arsenic-was at once ordered. I gave three minims of liquor arsenici hydrochloricus, with eight minims of tinctura ferri perchloridi and five minims of tinctura nucis vomicx, in infusion of calumba, three times a day; and I endeavoured to meet the dyspeptic symptoms by a carefully regulated diet and by the administration of bismuth and lactopeptine after each meal.

Improvement showed itself very gradually: at first, by an arrest of the vomiting and nausea; then, little by little, by a diminution of the apathy and lacklustre which characterised this patient so much; and finally by returning vigour and strength. In six weeks, he was able to sit up, at first for a few hours in bed, and afterwards in a chair; and then he could take solid food without vomiting; and the last symptom to yield was the occasional attack of gastric pain. With these

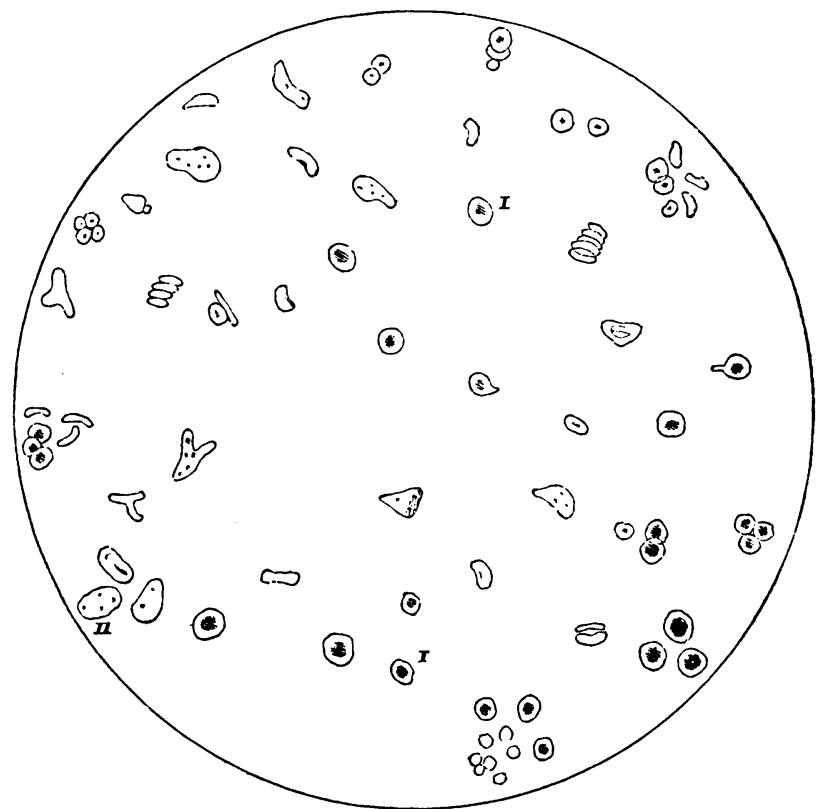

Fig. 2.-I represents a Normal" Red Corpusle. 11. A Normal White Corpuscle. The other irregular corpuscles were not all from one specimen, but were marked down from several fields as illustrating the varieties of size and shape.

special improvements, his colour changed to something approaching that of health, the corpse-like aspect passed away, and his eyes became intelligent and even cheerful. The blood, which was frequently examined while under observation, marked a steady return to that of health both as to colour and consistence; while the red corpuscles increased in number, and there was a diminution of the microcytes and other cells of abnormal shapes.

The patient left the hospital on September 29th, being able to walk down stairs and some short distance to the street. By my directions, the medicine was to be steadily persevered in for a considerable time. It happened, however, in this case, as has happened in many others, that once a patient leaves the constant oversight, regularity, and care of hospital, the medicine is omitted or altogether forgotten, and the progress to recovery retarded, if not arrested. Once or twice, indeed, his wife came for medicine, and reported improvement sufficient to enable him to undertake small jobs as a cobbler, but that his strength was not returning. It is, however, more than probable that, owing to his straitened circumstances, his diet fell short of what he had in hospital, both in quantity and in quality, as well as in the mode of its preparation. Nevertheless, on October 3 rst, 1878 , he was able to walk sixty yards when he paid me a visit, and his appearance had further improved. During the present year (I879), I have frequently heard of this patient; and on the 23rd of October last he was able to walk over a mile and a half to see me, and presented, for him, a remarkably healthy aspect. His lips, etc., were of a good red colour. He was well covered with fat, and his muscles were fairly developed. I examined his blood on that occasion, and found it perfectly healthy, with the exception of a few cells of abnormal size and one or two crenated corpuscles. This latter phenomenon I attribute to the unavoidable delay in submitting the specimen of blood to the microscope.

[To be continued.]

THE appointment of Surgeon-Major H. B. Spurgin of the Militia Medical Department to the Medical Charge of the 29th Brigade Depôt at Northampton is of interest, as being made under the provisions of Articles 49 and $5 \mathrm{I}$ of the recent Medical Warrant, and may perhaps suggest to some of our readers who are Militia Medical Officers applications for similar posts in their respective localities. 